\title{
Status of Women's Health in Goa and Sikkim: A Comparative Analysis of State Fact Sheets of National Family Health Survey (NFHS)-3 And 4
}

\author{
Ranjit Kumar Dehury ${ }^{1 *}$, Janmejaya Samal' ${ }^{2}$, Nafisa Vaze Desouza ${ }^{1}$, Parthsarathi Dehury ${ }^{3}$
}

\section{Ranjit Kumar Dehury ${ }^{1 *}$, Janmejaya Samal' ${ }^{2}$, Nafisa Vaz e Desouza', Parthsarathi Dehury ${ }^{3}$}

${ }^{1}$ Faculty- Health Care Management, Area Goa Institute of Management, Sanquilim Campus Panaji, Goa, INDIA. ${ }^{2}$ Medical Consultant-Urban TB Catholic Health Association of India (CHAl) Chhattisgarh, INDIA.

${ }^{3}$ PhD Scholar, Tata Institute of Social Sciences, Mumbai, Maharashtra, INDIA and Assistant Professor, Department of Social Work, Guru Ghasidas Vishwavidyalaya (A Central University of India), Bilaspur, Chhattisgarh, INDIA.

\section{Correspondence}

Ranjit Kumar Dehury

Faculty- Health Care Management Area, Goa Institute of Management Sanquilim Campus, Panaji, Goa, INDIA.

Mobile no: 91-7066049270

Email: ranjit@gim.ac.in, ranjitkumardehury@gmail.com

History

- Submission Date: 09-04-2017

- Revised Date: 14-06-2017

- Accepted Date: 10-11-2017

DOI : 10.5530/ijmedph.2017.4.41

Article Available online

http://www.ijmedph.org/v7/i4

\section{Copyright}

(C) 2017 Phcog.Net. This is an openaccess article distributed under the terms of the Creative Commons Attribution 4.0 International license.

\begin{abstract}
Objective: The main objective of this study was to assess the status of women's health in Goa and Sikkim based on the factsheets of NFHS-3 and NFHS-4. In addition, the study also compares and contrasts the achievements of reproductive health indicators in Goa and Sikkim. Methodology: The study adopted a descriptive analysis of NFHS fact sheets of Goa and Sikkim. The fact sheets were obtained from the web portal of NFHS at the International Institute of Population Sciences (IIPS), Mumbai and the indicators of women's health were then compared between NFHS-3 and 4. These indicators include marriage and fertility, ante-natal care (ANC) services, performance in neonatal tetanus and anaemia control, performance in mother and child protection card, post-natal care (PNC), delivery services, women's empowerment and gender based violence. Results: Despite remarkable progress observed from NFHS-3 to NFHS-4, many parameters pertaining women's health such as; access to maternal care, women's empowerment, and nutritional status still require further improvement. The progress in Sikkim is relatively sluggish compared to Goa however the status of women empowerment is relatively better in Sikkim. Better performance in several indicators in both these states need to be consolidated for achieving targets in the future. To further the improvement in these indicators requires a strong political commitment, continuous monitoring by competent authorities and mobilization of appropriate resources. Conclusion: The performance of Goa is relatively better compared to Sikkim. The indicators analysed in this study including access to resources strongly influence the health status and the empowerment of women which is linked with reproductive health outcomes. In addition both the fact sheets reveal that women in these two states take part in household decision making.

Key words: Antenatal Care, Delivery Care, Gender Based Violence, Maternal Health, Women's Empowerment.
\end{abstract}

\section{INTRODUCTION}

Women's health has always been a matter of concern for various societies. In most of the Indian communities gender inequality is marked remarkably. Moreover, there exists high regional disparity in Indian society. Various surveys carried out in India, at different times, show abysmal condition of Indian women in relation to access to health care services. Commonly comparative studies on bigger states, BIMARU and EAG (Empowered Action Group) states are found in India regarding access to health services for women. However a few studies are found on smaller states like north-eastern states, Goa, and union territories. Thus this necessitates a comparative analysis of smaller states like Sikkim and Goa. Both Goa and Sikkim are considered as developed states in India. Both these states are known for many tourism destinations in India and abroad as well. Goa is a costal state with mountains in the western side and Sikkim is a mountainous state with high rise of peeks.
Goa has a per capita GDP of \$ 3745 whereas Sikkim has \$1033. Goa got its full statehood in 1987 and Sikkim was a part of India as a state since 1975. The area of Goa is 3702 square kilo meter in comparison to Sikkim with 7096 square kilo meter. Goa consists of 2 districts in comparison to Sikkim with 4 districts. The population of Goa is almost double of Sikkim, the population Goa is 1.46 million compared to Sikkim with 0.6 million. The population density of Goa is 396 in comparison to 86 of Sikkim. Among Indian states Goa and Sikkim are ranked closer in terms of area and population. Goa and Sikkim ranked 28 and 27 respectively in terms of area. Whereas, Goa and Sikkim ranked 25 and 28 respectively in terms of population. The literacy rate of Goa is $87.4 \%$ in comparison to $82.2 \%$ of Sikkim. ${ }^{1}$

Both the states have relatively better sex ratio in comparison to national average of India. Goa has a sex ratio of 1018 in comparison to Sikkim being 942. Infra-
Cite this article : Dehury RK, Samal J, Desouza NV, Dehury P. Status of Women's Health in Goa and Sikkim: A Comparative Analysis of State Fact Sheets of National Family Health Survey (NFHS)-3 And 4. Int J Med Public Health. 2017;7(4):196-202. 
structuraland related developments are relativelybetterin both thesestates; $100 \%$ provision of electricity and improved water supply. The insurance coverage is also found to be very good at 95.7 and 99.6 in Goa and Sikkim respectively. All these socio-economic and demographic indicators, for both the states, fall within the similar range which provides a ground for comparison of women's health between these two states. ${ }^{1}$

Women's health and empowerment has a strong linkage for the overall development of a region. Moreover the health of women plays a paramount role in the socioeconomic development of any society. This has been observed by various studies that there is a strong linkage between improvement of women's health and related socioeconomic factors. ${ }^{2,3,4,5}$

Given the condition it would be useful to understand the situation of women's health of Sikkim and Goa by analysing the publicly available data. Given the similar status of human development index, the analysis can bring out the dynamics of women's health and assess the factors responsible for the overall progress. The recently published NFHS fact sheets show different outcomes of the women's health in Goa and Sikkim.

\section{OBJECTIVE}

The main objective of the study was to assess the status of women's health in Goa and Sikkim based on NFHS-3 and NFHS-4 fact sheets.

\section{METHODOLOGY}

The study adopted a descriptive analysis of women's health indicators based on the NFHS fact sheets obtained from appropriate sources. ${ }^{6,7}$ The data sets were compared with each other (NFHS-3 and NFHS-4) for various women's health related indicators in Goa and Sikkim. The indicators compared in this study includes marriage and fertility, ANC services, performance in anaemia, neonatal tetanus, performance in mother and child protection card, post-natal care, delivery services, women's empowerment and gender based violence. For the purpose of comparative analysis percentage distribution Tables were used and an interpretation was made from the figures. Efforts were also made to unearth various causes of the pattern of the data. The probable causes of the improvement or decline is also mentioned pertaining to the factsheets of Sikkim and Goa.

\section{RESULTS}

\section{Marriage and fertility}

Age at marriage is one of the factors that affects the women's health to a large extend. In India the legal age of marriage for women is 18 years. Almost one-tenth of women in Goa marry before the age of 18 with little improvement from NHFS-3 to NHFS-4. On the contrary almost $14.5 \%$ women in Sikkim get married before the age of 18 years. However a significant reduction in early marriage is being observed during these days as per the fact sheets of NHFS-3 and NHFS- 4 of Sikkim. Fertility rate of Goa and Sikkim are below the replacement level of 2.1. Goa shows a marginal reduction of fertility rate in comparison to Sikkim with a very significant reduction from 2 to 1.2 from NHFS-3 to NFHS-4. This may be an alarming condition for the socio-economic condition of Himalayan state of Sikkim. Teen age pregnancy is a concern for the health of mother and children. It has a long term crippling effect on the society as well. Goa is faring well in controlling teen age pregnancy in comparison to Sikkim. As per the NFHS-4 data only $2.9 \%$ teen age pregnancy is found in Goa compared to $12 \%$ in Sikkim. The details of the trends of marriage and fertility are shown in the Table $1.6,7$

\section{Use of Family Planning Methods}

Adoption of family planning methods is not just a means to curb population of the states but also provides huge dividend in terms of controlling sexually transmitted diseases, mortality and morbidity. In both of these states, a huge unmet need for contraceptives is being observed which has further repercussions on health of the women in long run. Compared to NFHS-3 data there has been reduction in the usage of any methods (including modern methods) of contraception in the data of NFHS-4 for both the states. Nearly half of the currently married women used any method of contraception for family planning in Goa, as per the data of NFHS-3, whereas only one quarter uses any methods of contraception, as per the data of NFHS-4. There has been a reduction of one-tenth (from $57.6 \%$ to $46.7 \%$ ) of currently married women in the usage of any method in Sikkim.

The usage of any of the modern methods of contraception has also been decreased from NFHS-3 to NFHS-4 for both the states. Sikkim has less utilization than Goa in terms of the usage of modern family planning methods (Goa has $24.8 \%$ in comparison to Sikkim having 17.6\%) among the currently married couples. There has also been decreased adoption of female sterilization in both these states as per the data of NFHS-4 compared to NFHS-3. Goa and Sikkim have similar rate of adoption of female sterilization rate as per NFHS- 4 data. Male sterilization is a cause of concern for both these states. There is no male sterilization happening in Goa compared to minimum of Sikkim (at 3.4\%). The usage of IUD (Intra Uterine Devices)/PPIUD (Post Partum Intra Uterine Devices) as a method of family planning for Goa shows a negative trend (from 2.3\% to $0.9 \%)$, whereas Sikkim has shown a positive trend (3.0\% to $6.3 \%)$ in the adoption of IUD/PPIUD as a method of family planning. The usage of oral pills as a method of family planning shows encouraging figure for Sikkim compared to Goa (Sikkim at 11.7 and Goa at $0.3 \%$ ) according to NFHS- 4 data. The use of condom as a contraceptive method remains low (Sikkim at 5.2\% and Goa at 7.1\%) for both the states according to NFHS4 data. The details of the trend are shown in the Table 2.6,7

\section{Accessing the maternal Health Care services}

Antenatal check-up is an important aspect for maternal healthcare for healthy pregnancy outcome. The guidelines emphasizes for 4 mandatory ANC (Ante natal care) to ensure safe maternal and foetal outcome. ANC in first trimester helps in yielding positive health of mother. Goa has better ANC care (Sikkim at $76.2 \%$ and Goa at $84.4 \%$ ) than Sikkim according to NFHS-4 data. However Sikkim has improved its performance from $57.9 \%$ to $76.2 \%$ from NFHS-3 to NFHS- 4 . Goa does not show increase of at least 4 ANCs in the data of NFHS-4 compared to NHFS-3, whereas Sikkim shows increased trend of at least 4 ANCs in the data of NFHS- 4 compared to NHFS-3 (from $56.2 \%$ to $74.7 \%$ ). The data infers that in Goa one-tenth of the pregnant women do not receive 4 ANC in comparison to one-quarter of the pregnant women according to NHFS-4 data. The protection of mothers against neonatal tetanus is promising for both the states according to NHFS-4 data (Goa at $96.2 \%$ and Sikkim at $97.2 \%)$.

In Sikkim the consumption of iron and folic acid (IFA) is much lower, half of the women are protected against anaemia in comparison $67.4 \%$ of women for Goa, as per the NFHS-4data. However, Sikkim is able to increase the usage of IFA by almost 2 times compared to NFHS-3 data.

Full antenatal care (ANC) consists of at least four antenatal visits, at least one tetanus toxoid (TT) and provision of IFA tablets or syrup for 100 or more days for care of the pregnant women. While Goa managed to increase full ANC by around 6\% from NHFS-3 to NHFS-4, Sikkim shows a robust trend for this component during the same survey period (from $22.4 \%$ to $39.0 \%$ ).

Mother and Child Protection (MCP) card is adopted to monitor the status of maternal health for provision of services. Albeit both the states show a good performance in documenting the MCP card for the 


\begin{tabular}{|c|c|c|}
\hline Name of the State & NFHS-3 & NFHS-4 \\
\hline \multicolumn{3}{|c|}{ Women age 20-24 years married before the age of 18 years (\%) } \\
\hline Goa & 11.7 & 9.4 \\
\hline Sikkim & 30.1 & 14.5 \\
\hline \multicolumn{3}{|c|}{ Total fertility rate (children per woman) } \\
\hline Goa & 1.8 & 1.7 \\
\hline Sikkim & 2.0 & 1.2 \\
\hline \multicolumn{3}{|c|}{$\begin{array}{l}\text { Women age 15-19 years who were already mothers or pregnant at the time } \\
\text { of the survey (\%) }\end{array}$} \\
\hline Goa & 3.6 & 2.9 \\
\hline Sikkim & 12 & 12.0 \\
\hline
\end{tabular}

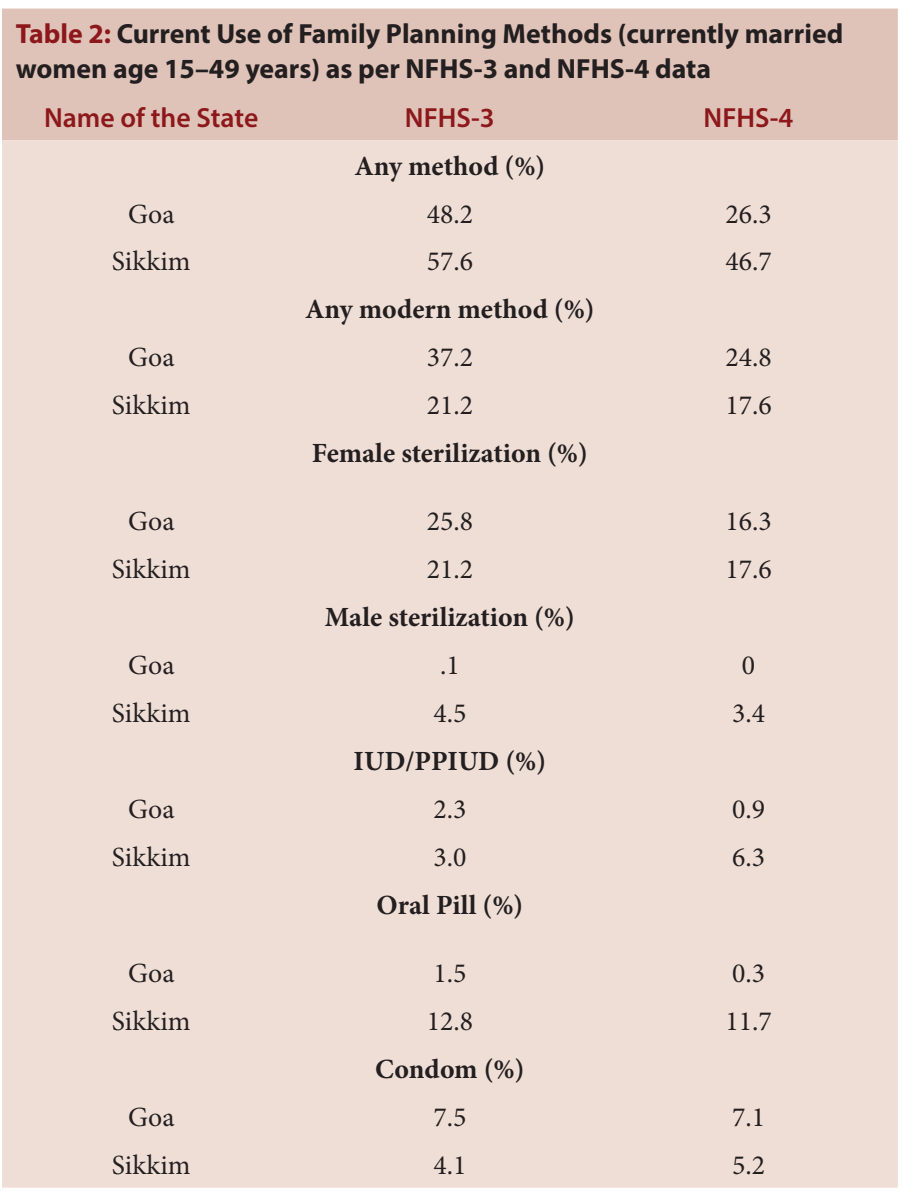

pregnant mothers in comparison to national average however Sikkim fares better than Goa as per the NFHS-3 and NHFH-4 data.

The children born at home by regular cheek-up by health facilities within 24 hours of birth in both the states is satisfactory. The care given by doctor/nurse/LHV (Lady Health Visitor)/ANM (Auxiliary Nurse Midwife) / midwife/other health personnel within 2 days of birth is increased $75.3 \%$ to $92.1 \%$ in Goa and $44.9 \%$ to $74.2 \%$ in Sikkim, as per NFHS-3 to NFHS-4. The detailed trend of availing maternal health services is shown in the Table $3{ }^{6,7}$

\section{Table 3: Accessing the Maternal Health Care services in Goa and} Sikkim as per NFHS-3 and NFHS-4

Name of the NFHS-3 NFHS-4
State

Mothers who had antenatal check-up in the first trimester (\%)

$\begin{array}{ccc}\text { Goa } & 85.7 & 84.4 \\ \text { Sikkim } & 57.9 & 76.2\end{array}$

Mothers who had at least 4 antenatal care visits (\%)

$\begin{array}{ccc}\text { Goa } & 92.4 & 89.0 \\ \text { Sikkim } & 56.2 & 74.7\end{array}$

$\%$ of mothers whose last birth was protected against neonatal tetanus

$\begin{array}{ccc}\text { Goa } & 86.8 & 96.2 \\ \text { Sikkim } & 81.1 & 97.2\end{array}$

$\%$ of mothers who consumed IFA for 100 days or more when they were pregnant

$\begin{array}{ccc}\text { Goa } & 59.6 & 67.4 \\ \text { Sikkim } & 26.3 & 52.8 \\ \text { State } & \text { NFHS-3 } & \text { NFHS-4 } \\ & \text { Mothers who had full ANC (\%) } \\ \text { Goa } & 57.4 & 63.4 \\ \text { Sikkim } & 22.4 & 39.0\end{array}$

Registered pregnancies for which the mother received Mother and Child Protection Mother and Child Protection card (\%)

$\begin{array}{ccc}\text { Goa } & \text { NA } & 96.3 \\ \text { Sikkim } & \text { NA } & 99.1\end{array}$

$\%$ of mothers who received postnatal care from a doctor/nurse/LHV/ANM/ midwife/other health personnel within 2 days of delivery
Goa
75.3
92.1
Sikkim
44.9
74.2

\section{Delivery Care}

The institutional delivery in both Goa and Sikkim has increased as reported by NFHS-4 compared to NFHS-3. The JSY (Janani Suraksha Yojna) program has a strong impact in both the states. However, Sikkim shows better increase of intuitional delivery compared to Goa in the figures of NFHS- 4 compared to NFHS-3 (Sikkim from 47.2 to $94.7 \%$ and Goa from $92.3 \%$ to $96.9 \%$ ). Institutional deliveries at public health facilities is happening more in Sikkim than Goa (Sikkim- 82.7\% and Goa- 58.2\%) according to NFHS-4 data. The percentage of home deliveries to total deliveries is low in both the states and has been decreasing. This is a good sign that people in both these states are adopting institutional delivery.

Deliveries conducted by doctor/nurse/LHV/ANM/other health personnel in both the states are quite good. Sikkim shows a trend of three quarter of institutional assisted delivery by skilled personnel to almost $100 \%$ percent coverage as per the data of NHFS-3 to NFHS-4.

Caesarean section (CS) deliveries are alarmingly high for Sikkim at $20.9 \%$ according to NHFS-4 data which has been increased from $12.3 \%$ of NHFS-3. However, CS deliveries decreased in Goa (from $31.4 \%$ of NFHS-3 to $6.2 \%$ of NFHS- 4 ). The WHO standard for CS ranged from $5-15 \%$ of the total deliveries. However, there is high rate of CS deliveries being conducted in private facilities than in public facilities in both these states between NFHS-3 and NFHS-4. The detailed trend is shown in the Table $4 .^{6,7}$ 


\begin{tabular}{|c|c|c|}
\hline State & NFHS-3 & NFHS-4 \\
\hline \multicolumn{3}{|c|}{$\%$ of institutional deliveries } \\
\hline Goa & 92.3 & 96.9 \\
\hline Sikkim & 47.2 & 94.7 \\
\hline \multicolumn{3}{|c|}{$\%$ of institutional births in public facilities } \\
\hline Goa & 43.2 & 58.2 \\
\hline Sikkim & 44.5 & 82.7 \\
\hline \multicolumn{3}{|c|}{$\%$ of home deliveries conducted by skilled birth attendants (SBA) } \\
\hline Goa & 1.9 & 1.8 \\
\hline Sikkim & 6.5 & 2.4 \\
\hline \multicolumn{3}{|c|}{$\%$ of births assisted by a doctor/nurse/LHV/ANM/other health personn } \\
\hline Goa & 94.0 & 97.5 \\
\hline Sikkim & 53.7 & 97.1 \\
\hline \multicolumn{3}{|c|}{$\%$ of total caesarean section deliveries } \\
\hline Goa & 31.4 & 6.2 \\
\hline Sikkim & 12.3 & 20.9 \\
\hline \multicolumn{3}{|c|}{$\%$ of caesarean section in private facilities } \\
\hline Goa & 36.7 & 51.3 \\
\hline Sikkim & na & 49.3 \\
\hline \multicolumn{3}{|c|}{$\%$ of caesarean section public health facilities } \\
\hline Goa & 17.9 & 19.9 \\
\hline Sikkim & 25.0 & 18.1 \\
\hline
\end{tabular}

\section{Nutritional status and anaemia}

Nutritional status of women is very important for the overall development of health status of women. Poor nutritional status mostly leads to anaemia and causes high maternal mortality and morbidity. Both underweight and overweight causes a concern for the poor development of women. The body mass index (BMI) is a measure which shows the nutritional status of human being. There is a reduction of percentage of women whose BMI is below normal in both Goa and Sikkim from NFHS-3 to NFHS-4 data. However, Sikkim is performing better than Goa in terms of the undernourishment (Sikkim- 6.4\% and Goa- 14.7\%). Regarding the percentage of women who are overweight or obese, again, Sikkim performs better (Sikkim-33.5 and Goa- 26.7\%) according to NFHS-4 data. However, there is poor performance of both the stats as per the data of NFHS- 4 to NFHS-3.

The anaemia of children within the age group of 6-59 months is a cause of concern for both the states. Roughly half of the children are suffering from anaemia according to the data of NFHS-4. While Sikkim shows a marginal decrease of anaemia, there is an increase of $20 \%$ for Goa in the data of NFHS-4 in comparison to NHFS-3 data.

The anaemia of non-pregnant women aged 15-49 years is also alarming for both the states with roughly one-third of them are suffering from anaemia. However, the silver line is that pregnant women suffer marginally lower within the same age group of 15-49 years according to the data of NHFS-4. The reduction of percentage of pregnant women with anaemia is quiet significant among the pregnant women for Sikkim from NHFS-3 to NHFS-4 (62.15\% to $23.6 \%)$. The detailed trend is shown in the Table $5 \cdot{ }^{6,7}$

\section{Women's Empowerment and Gender Based Violence}

Women's empowerment is an important role in the society for better reproductive health outcomes. The equitable distribution of resources among the population is needed for better provisioning of health care services. The age old discrimination against women gets reflected in terms of various development indicators of women. Taking part in household decision making by women usually leads to a gender sensitive society. Both Goa and Sikkim has a good track record of women' participation in house hold decision making according to NFHS-3 and NFHS-4 data. Sikkim shows relatively better performance than Goa (Sikkim $-95.3 \%$ and Goa- $93.8 \%$ ) in accommodating the decision of women in household activities.

Payment of wage is a tangible resource for strengthening of financial condition. If women receive wage in cash, it would empower them to take various decisions with financial implications. The payment in cash has been decreased from NFHS- 3 to NFHS- 4 for both the states. This may be due to the minimization of cash transactions in favour of account payment by banks and post offices.

Spousal violence is a common finding in Indian society which curtails the power of women. This is an inhuman practice for the development of society. This is a human right concern for the entire society having repercussion on the health of women. The spousal violence has been decreased from NFHS-3 to NFHS- 4 for both the states. The decrease is marginal for Goa ( $16.3 \%$ to $12.9 \%$ from NFHS-3 to NFHS-4) and is substantial for Sikkim (16.8\% to $2.6 \%$ from NFHS-3 to NFHS-4).

Violence during pregnancy is a critical situation for the women and child. The vulnerability is more due to the special condition of pregnancy which may lead to abortion and other mal-function of child. The NHFS4 data shows higher violence existing in Goa than Sikkim (Goa-1.6\% and Sikkim- 0.4\%) during pregnancy.

Ownership of house and land provide a sense of security to women. This immovable property may be utilized at the time of emergency due to various socio-economic crises. The women of Goa have a fairer share in the ownership of land and houses than Sikkim according to NHFS-4 data (Goa-33.9\% and Sikkim-24.8\%).

Having a bank account and good saving on it provides seamless independence to women. It would help in crises of health and wellbeing. Both the states have shown good increase in the holding of bank accounts among women from NHFS-3 to NHFS-4 data. However, more women of Goa have own the bank accounts than Sikkim according to NHFS-4 data (Goa $-82.8 \%$ and Sikkim-63.5\%).

Almost four-fifth of the women has mobile phones in both the states according to NHFS- 4 data. The usage of hygienic sanitary methods during the menstrual period is required for good health and minimization of morbidity. More women of Goa have this protection than Sikkim according to NHFS-4 data (Goa- $89.3 \%$ and Sikkim- $86.6 \%$ ). The detailed trend is shown in the Table 6. ${ }^{6,7}$

\section{DISCUSSION}

Teen age marriage is a concern for the Himalayan state of Sikkim where almost $15 \%$ of the girls are getting married below the legal age of 18 . Early marriage has got various consequences in maternal health as well as women's empowerment. Precisely speaking early marriage has got two important concerns; medical and social. The medical concern is related to early child bearing and related reproductive health problems and the social concern is related with the social intercourse where an immature adolescent may not be capable enough to handle the family intricacies resulting in dominancy by husband and in-laws which may lead to domestic violence and related problems as well. As per the current NFHS data Goa is performing well in these parameters. Various studies 


\begin{tabular}{|c|c|c|}
\hline State & NFHS-3 & NFHS-4 \\
\hline \multicolumn{3}{|c|}{$\begin{array}{l}\text { Women whose Body Mass Index (BMI) is below normal (BMI }<18.5 \mathrm{~kg} / \\
\mathrm{m} 2)(\%)\end{array}$} \\
\hline Goa & 27.9 & 14.7 \\
\hline Sikkim & 11.2 & 6.4 \\
\hline \multicolumn{3}{|c|}{ Women who are overweight or obese (BMI $\geq 25.0 \mathrm{~kg} / \mathrm{m} 2) 14$ (\%) } \\
\hline Goa & 20.2 & 33.5 \\
\hline Sikkim & 15.4 & 26.7 \\
\hline \multicolumn{3}{|c|}{ Children age 6-59 months who are anaemic $(<11.0 \mathrm{~g} / \mathrm{dl})(\%)$} \\
\hline Goa & 38.2 & 48.3 \\
\hline Sikkim & 58.1 & 55.1 \\
\hline \multicolumn{3}{|c|}{ Non-pregnant women age $15-49$ years who are anaemic $(<12.0 \mathrm{~g} / \mathrm{dl})(\%)$} \\
\hline Goa & 37.9 & 31.4 \\
\hline Sikkim & 59.4 & 35.2 \\
\hline \multicolumn{3}{|c|}{ Pregnant women age $15-49$ years who are anaemic $(<11.0 \mathrm{~g} / \mathrm{dl})(\%)$} \\
\hline Goa & 36.9 & 26.7 \\
\hline Sikkim & 62.1 & 23.6 \\
\hline \multicolumn{3}{|c|}{ All women age $15-49$ years who are anaemic (\%) } \\
\hline Goa & 38.0 & 31.3 \\
\hline Sikkim & 59.5 & 34.9 \\
\hline
\end{tabular}

substantiate the association between early age of marriage and its relevance with the social and medical concerns in Indian communities. ${ }^{8,9,10,11}$ Thus it is imperative to implement various measures like community level awareness programmes to minimize the early marriage.

Sikkim has a low consumption of iron and folic acid (IFA) Tablets which amount to only half of women being protected against anaemia in comparison to Goa. A systematic review suggests that in malaria prone areas routine IFA should be provided to adolescent population. ${ }^{12}$ As Goa is prone to malaria which affects the health of the mother thus they should be provided with IFA regularly and their consumption should be improved through various advocacy and communication measures. Furthermore child care and maternal care depend on the status of haemoglobin level which could be supplemented by IFA. In addition the NFHS-2 data analysis for rural India reveals that the maternal characteristics relating to socio-economic and behavioural factors affect the childhood nutrition. ${ }^{13}$ Such problems exist in rural areas more than the urban areas.

Sikkim fares better than Goa in receiving Mother and Child Protection (MCP) card which is adopted to monitor the status of maternal health for provision of appropriate health services. The MCP card has got a major role in maternal well being and thereby the foetal wellbeing. It can serve as a ready reference during ANCs and during the time of labour as well and help make medical decisions during these periods.

According to the current NFHS data the children born at home by regular cheek-up by health facilities within 24 hours of birth in both the states is satisfactory. However it is always advisable to increase the institution based deliveries than that of the home deliveries as the latter carries more maternal and foetal risk compared to the former one. Albeit the institutional deliveries are in increasing trend in Indian states however the rural areas need more sensitization and awareness to increase the institutional deliveries. Institutional deliveries at public health care institutions are more in Sikkim than Goa according to NFHS-4. This shows the satisfac-

\section{Table 6: Women's Empowerment and Gender Based Violence (age 15-49 years) in Goa and Sikkim as per NFHS-3\&4 \\ State}

NFHS-3

NFHS-4

Currently married women who usually participate in household decisions (\%)

$\begin{array}{lll}\text { Goa } & 91.1 & 93.8\end{array}$

Sikkim $\quad 93.6-95.3$

Women who worked in the last 12 months who were paid in cash (\%)

$\begin{array}{lll}\text { Goa } & 33.2 & 23.6\end{array}$

$\begin{array}{lll}\text { Sikkim } & 22.0 & 19.9\end{array}$

Ever-married women who have ever experienced spousal violence (\%)

$\begin{array}{lll}\text { Goa } & 16.8 & 12.9\end{array}$

Sikkim

16.3

2.6

Ever-married women who have experienced violence during any pregnancy (\%)

Goa

NA

1.6

Sikkim

NA

.4

Women owning a house and/or land (alone or jointly with others) (\%)

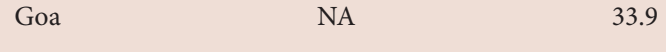

Sikkim NA 24.8

Women having a bank or savings account that they themselves use (\%)

$\begin{array}{ccc}\text { Goa } & 42.4 & 82.8 \\ \text { Sikkim } & 20.9 & 63.5\end{array}$

Women having a mobile phone that they themselves use (\%)

$\begin{array}{lll}\text { Goa } & \text { NA } & 80.9\end{array}$

$\begin{array}{lll}\text { Sikkim NA } \quad 79.8 & \text { NA }\end{array}$

Women age 15-24 years who use hygienic methods of protection during their menstrual period (\%)

$\begin{array}{ccc}\text { Goa } & \text { NA } & 89.3 \\ \text { Sikkim } & \text { NA } & 84.6\end{array}$

${ }^{*}$ NA-Not available

tory conditions of Sikkim government health facilities. Goa government has to aware the population to avail government health facilities and ensure sufficient good quality care.

So far, Caesarean section (CS) deliveries are concerned Sikkim shows a high trend at $20.9 \%$ according to NHFS- 4 data. This is an emerging trend in India which impoverishes patients and lead to unhealthy trend of increasing CS. A systematic review reports that sometimes personal and social regions are responsible for increase in CS which include fear of birth and perceived unequal and inadequate care in health centres. ${ }^{14}$ One of the researches argues that the risk-benefit must be assessed to take a decision on CS. This must be shared with the patient also. ${ }^{15}$ It has been suggested that to improve maternal and child health CS should be adopted strictly based on medical indications. ${ }^{16}$ In Goa and Sikkim context there is also a greater need to mull over the increasing trend of CS cases. Nutritional status is one of the important factors for development of women. Sikkim is performing better than Goa in terms of the managing undernourishment. Further, Sikkim performs better in managing women who are overweight or obese. Goa has to improve these parameters for betterment of the health situations relating to nutrition of women..$^{17,18,19}$ A cohort study in a district hospital of Goa found that psychological disorder and depression of mother are also linked with nutritional status 
of children. ${ }^{20}$ Similarly a systematic review shows that nutritional burden of women between pregnancies depends on the extent of breastfeeding, and spacing between pregnancies. Thus it is clear that birth spacing affect the nutritional status of women and children. ${ }^{21}$ Short inter-pregnancy interval affects the nutritional status of women. ${ }^{22}$ This is particularly important for the health and nutrition of the entire population. This not just affects the children but also has a long term impact on the adolescent health.

Women's empowerment plays an important role in the society for better reproductive health. Both Goa and Sikkim has a good track record of women' participation in house hold decision making according to NFHS-3 and NFHS-4 data. Here Sikkim shows relatively better performance than Goa for accommodation of the decision of women in household activities. Spousal violence is taken a as measure to find out the power of women. The spousal violence has been decreased from NFHS-3 to NFHS-4 for both the states. However, the decrease is marginal for Goa and is substantial for Sikkim. This shows the receptivity of Sikkim as a progressive society. The women of Goa have a better share in the ownership of land and houses than Sikkim as per the data of NHFS-4. Goa's women have better access to financial liberty assuming that holding a bank account provides financial liberty. Overall, the gender equality is at similar level for Goa and Sikkim. Various studies also agree that women's empowerment provides better access to health and wellness. ${ }^{23,24,25}$ The Sikkim model of empowerment by involving woman in various small and medium scale industry have always got good returns. Moreover Goa's open culture and assertiveness of women brings out the sense of empowerment among women. Governmental regulations to protect women and provide equal opportunity in Goa offer a substantive empowerment to the women of Goa.

Furthermore studies revealed that use of emergency contraceptive pills in Sikkim is low among illiterate women. However, electronic media, friends and relatives, and health personnel play an important role in disseminating health information. ${ }^{26}$ In East Sikkim district the use of male contraceptive methods is quite high, showing a greater degree of involvement of male in reproductive health matters, indicating a non-patriarchal approach to reproductive health which is not the case with many Indian societies and almost nonexistent in Northern Indian states. This is an indication of women empowerment and sharing of equal burden in reproductive health matters. In addition socio demographic features also determine the use of contraceptive methods among female and male of Sikkim. ${ }^{27}$ These study findings have a strong correlation for the overall development of health of women of Sikkim. ${ }^{28}$

On the contrary a cross sectional study in Goa revealed that some cultural factors like gender preference and the lack of involvement of husbands in caring of child happened to be the major causes of stress among the mothers. ${ }^{29}$ Socially marginalized women of Goa are found to be at more risk of HIV infection within the marriage. The study suggests that effective screening and treatment of men is required for safe sex within marriage. ${ }^{30}$ An urgent need is felt in Goa for the improvement of maternal health by partnering with private sector, effective provision of cash transfer to the pregnant women, and monitoring of public health facilities for reducing the financial distress among women. ${ }^{31}$

\section{CONCLUSION}

There are various parameters on which Goa fares better. Access to various resources plays an important role in the overall development of women. All the analysed parameters have a direct or indirect impact on the health and empowerment of women. Sikkim has a low consumption of iron and folic acid (IFA) compared to only half of women protected against anaemia in Goa. Nutritional status is one of the important factors for the overall development of women. Performance of Sikkim is better than
Goa in terms of the undernourishment. Women's empowerment plays an important role in the society for the betterment of reproductive health. Noteworthy to mention that both of these states have good track record of women' participation in house hold decision making.

\section{ACKNOWLEDGEMENT}

Authors express gratitude to the team of researchers at International Institute of Population Studies, Mumbai, INDIA, Goa Institute of Management Panaji, INDIA, and Development \& Research Services Pvt. Ltd. (DRS), New Delhi, INDIA for collecting primary data pertaining to Goa and Sikkim and availing it for the analysis.

\section{CONFLICT OF INTEREST}

There are no conflicts of interest.

\section{ABBREVIATION USED}

NFHS: National Family Health Survey; BIMARU: Acronym for states of Bihar; Madhya Pradesh, Rajasthan, and Uttar Pradesh; EAG: Empowered Action Group States; ANC: Antenatal Care; PNC: Post Natal Care; IFA: Iron and Folic Acid; MCP: Mother and Child Protection; GDP: Gross Domestic Product; IUD: Intra Uterine Devices; PPIUD: PostPartum Intra Uterine Devices; TT: Tetanus Toxoid; LHV: Lady Health Visitor; ANM: Auxiliary Nurse Midwife; JSY: Janani Suraksha Yojna; CS: Caesarean Section; BMI: Body Mass Index.

\section{REFERENCES}

1. Comparison of Sikkim and Goa. 2016. http://states-ofindia.findthebest.in/compare/6-23/Goa-vs-Sikkim

2. Verguet S, Nandi A, Filippi V, Bundy DA. Maternal-related deaths and impoverishment among adolescent girls in India and Niger: findings from a modelling study. BMJ Open. 2016;6(9):e011586.

3. Kulkarni VS, Kulkarni VS, Gaiha R. "Double Burden of Malnutrition" Reexamining the Coexistence of Undernutrition and Overweight among Women in India. International Journal of Health Services. 2016:0020731416664666.

4. Kumar C, Singh PK, Singh L, Rai RK. Socioeconomic disparities in coverage of full immunisation among children of adolescent mothers in India, 1990-2006: a repeated cross-sectional analysis. BMJ open. 2016;6(8):e009768.

5. Awasthi A, Pandey CM, Chauhan RK, Singh U. Disparity in maternal, newborn and child health services in high focus states in India: a district-level crosssectional analysis. BMJ open. 2016;6(8):e009885.

6. International Institute for Population Sciences. National Family Health Survey-4, State fact sheet Sikkim, 2015 -16: India. Mumbai: IIPS; 2016. Retrieved from: http://rchiips.org/NFHS/pdf/NFHS4/SK_FactSheet.pdf.

7. International Institute for Population Sciences. National Family Health Survey-4, State fact sheet Goa, 2015 -16: India. Mumbai: IIPS; 2016. Retrieved from: http://rchiips.org/NFHS/pdf/NFHS4/GA_FactSheet.pdf.

8. Majumder N, Ram F. Explaining the Role of Proximate Determinants on Fertility Decline among Poor and Non-Poor in Asian Countries. PloS one. 2015;10(2):e0115441.

9. Goli S, Rammohan A, Singh D. The Effect of Early Marriages and Early Childbearing on Women's Nutritional Status in India. Maternal and child health journal. 2015;19(8):1864-80.

10. Raj A, Saggurti N, Balaiah D, Silverman JG. Prevalence of child marriage and its effect on fertility and fertility-control outcomes of young women in India: a cross-sectional, observational study. The Lancet. 2009;373(9678):1883-9.

11. Kulkarni PM, Rani S. Recent fertility declines in China and India: a comparative view. Asia-Pacific Population Journal. 1995;10(4):53-74.

12. Pasricha S, Shet A, Sachdev HP, Shet AS. Risks of routine iron and folic acid supplementation for young children. Indian Pediatrics vol-46.

13. Rajaram S, Zottarelli LK, Sunil TS. Individual, household, programme and community effects on childhood malnutrition in rural India. Maternal \& child nutrition. 2007;3(2):129-40.

14. McCourt C, Weaver J, Statham H, Beake S, Gamble J, Creedy DK. Elective cesarean section and decision making: a critical review of the literature. Birth 2007;34(1):65-79

15. Ecker JL, Frigoletto Jr FD. Cesarean delivery and the risk-benefit calculus. New England Journal of Medicine. 2007;356(9):885-8.

16. Lumbiganon $P$, Laopaiboon M, Gülmezoglu AM, Souza JP, Taneepanichskul S Ruyan P, Attygalle DE, Shrestha N, Mori R, Hinh ND, Bang HT. Method of delivery and pregnancy outcomes in Asia: the WHO global survey on maternal and 
perinatal health 2007-08. The Lancet. 2010;375(9713):490-9.

17. Debnath $A$, Bhattacharjee N. Understanding Malnutrition of Tribal Children in India: The Role of Women's Empowerment. Ecology of Food and Nutrition. 2016:1-20

18. Chaturvedi S, Ramji S, Arora NK, Rewal S, Dasgupta R, Deshmukh V. Timeconstrained mother and expanding market: emerging model of under-nutrition in India. BMC Public Health. 2016;16(1):632.

19. Johri M, Subramanian SV, Koné GK, Dudeja S, Chandra D, Minoyan N, et al. Maternal Health Literacy Is Associated with Early Childhood Nutritional Status in India. The Journal of Nutrition. 2016:jn226290.

20. Patel V, Rodrigues M, De Souza N. Gender, poverty and post-natal depression: a cohort study from Goa, India. Am J Psychiatry2002;159(1):43-7.

21. Dewey KG, Cohen RJ. Does birth spacing affect maternal or child nutritional status? A systematic literature review. Maternal \& child nutrition. 2007;3(3):151-73.

22. Wendt A, Gibbs CM, Peters S, Hogue CJ. Impact of Increasing Inter-pregnancy Interval on Maternal and Infant Health. Paediatric and perinatal epidemiology. 2012;26(s1):239-58.

23. Kishor S, Gupta K. Gender equality and women's empowerment in India. National Family Health Survey (NFHS-3) India 2005-06.

24. Desai S, Jain D. Maternal employment and changes in family dynamics: The social context of women's work in rural South India. Population and Development Review. 1994:115-36.

25. Sen G, Östlin P. Gender inequity in health: why it exists and how we can change it. 2008.

26. Rahman H, Khalda E, Kar S, Kharka L, Bhutia GP. Knowledge of, at- titudes toward, and barriers to the practice of emergency contraception among women in Sikkim, India. International Journal of Gynecology Obstetrics. 2013;122(2):99-103.

27. Chankapa YD, Pal R, Tsering D. Male Behavior Toward Reproductive Responsibilities in Sikkim. Indian Journal of Community Medicine: Official Publication of Indian Association of Preventive Social Medicine. 2010;35(1):40-45. doi:10.4103/0970-0218.62552.

28. Chankapa YD, Tsering D, Kar S, Basu M, Pal R. Sociodemographic variables of contraceptive practice in Sikkim. Journal of Pharmacy and Bioallied Sciences. 2011;3(3):368-374. doi:10.4103/0975-7406.84439.

29. Rodrigues M, Patel V, Jaswal S, De Souza N. Listening to mothers: qualitative studies on motherhood and depression from Goa, India. Social Science Medicine. 2003;57(10):1797-806.

30. Weiss HA, Patel V, West B, Peeling RW, Kirkwood BR, Mabey D. Spousal sexual violence and poverty are risk factors for sexually transmitted infections in women: a longitudinal study of women in Goa, India. Sexually Transmitted Infections. 2008 Apr 1;84(2):133-9.

31. Bonu S, Bhushan I, Rani M, Anderson I. Incidence and correlates of 'catastrophic'maternal health care expenditure in India. Health Policy and Planning. 2009;24(6):445-56.

Cite this article : Dehury RK, Samal J, Desouza NV, Dehury P. Status of Women's Health in Goa and Sikkim: A Comparative Analysis of State Fact Sheets of National Family Health Survey (NFHS)-3 And 4. Int J Med Public Health. 2017;7(4):196-202. 